\title{
Incontinentia pigmenti en Cajamarca: Reporte de un caso en lactante
}

Brayan Gálvez-Marticorena ${ }^{1 a}$, Javier Chambi-Torres ${ }^{1 a}$

\section{RESUMEN}

La Incontinentia pigmenti (IP) o Síndrome de Bloch-Sulzberger es una rara enfermedad dominante ligada al cromosoma X, caracterizada por lesiones en la piel. Puede estar acompañada de manifestaciones neurológicas, oftalmológicas y dentales.

Se presenta el caso clínico de una lactante de un mes y veintiséis días diagnosticada con esta enfermedad y tratada con éxito. (Horiz Med 2015; 15(3): 57-60)

Palabras clave: Síndrome de Bloch-Sulzberger, Incontinencia Pigmentaria, hiperpigmentación (Fuente: DeCS BIREME).

Incontinentia pigmenti in Cajamarca: A case report on infant

\section{ABSTRACT}

Incontinentia pigmenti (IP) or Bloch-Sulzberger syndrome is a rare dominant X-linked disease characterized by skin lesions. It may be accompanied by neurological, ophthalmological and dental manifestations.

We report the case of a one month and twenty six days old female patient diagnosed with this disease who was successfully treated. (Horiz Med 2015; 15(3): 57-60)

Key words: Incontinentia pigmenti, Pigmentation Disorders, Skin Abnormalities (Source: MeSH NLM).

Estudiante de pre grado de Medicina Humana. Facultad de Medicina Humana. Universidad de San Martín de Porres. Lima-Perú

Sociedad Científica de Estudiantes de Medicina de la Universidad de San Martín de Porres: SOCIEM-USMP, Lima-Perú 


\section{INTRODUCCIÓN}

La Incontinentia pigmenti (IP) o Síndrome de BlochSulzberger es una rara enfermedad dominante ligada al cromosoma $X$ con una prevalencia estimada de 0,2/100,000 nacidos (1).

Frecuentemente causa alteraciones dérmicas, que se inician en el período neonatal con una erupción vesicular (estadio I) y tres etapas más (que van de meses a años) que comprenden una verrugosa (estadio II), la hiperpigmentada (estadio III), y finalmente la atrófico hipopigmentado (estadio IV) que generalmente continua a lo largo de la vida (2).

Las alteraciones dérmicas siguen las líneas de Blaschko y son el principal criterio de diagnóstico para IP según Landy y Donnai en 1993 (2).

La IP es casi exclusivo en las mujeres, debido a que es letal para los varones in útero (2). Éstos pueden sobrevivir si su cariotipo es 47XXY o si presentan una mutación hipomórfica (3).

No se conoce la prevalencia de IP en el Perú, pero existen casos reportados.

Presentamos este inusual caso con el fin de dar a conocer sus rasgos clínicos para el diagnóstico y tratamiento acertado.

\section{CASO CLÍNICO}

Lactante femenino de 1 mes 26 días, mestiza, primogénita de parto eutócico, natural de Cajamarca, Perú.

Presenta múltiples lesiones maculares hiperpigmentadas en tronco y extremidades, de distribución lineal, siguiendo las líneas de Blaschko (Figura 1), con lesiones verrugosas en al gunas zonas eritematosas sobre todo en los pliegues (Figura 2). Algunas cicatrices atróficas y otras queloides secuelares.

No se ve afectado el rostro ni palmas ni plantas. El resto del examen físico fue normal. Exámenes de laboratorio normales. Se le realizó una biopsia de piel (Figura 3).
Se determinó el diagnóstico de IP y el tratamiento inicial fue con una combinación de tacrolimus $0.03 \%$ tópico y mometazona tópica, hasta lograr la resolución total de las lesiones.

Fue seguida mes a mes, hasta el año de edad, presentó evolución favorable excepto las máculas hiperpigmentadas que se mantuvieron sin variación.

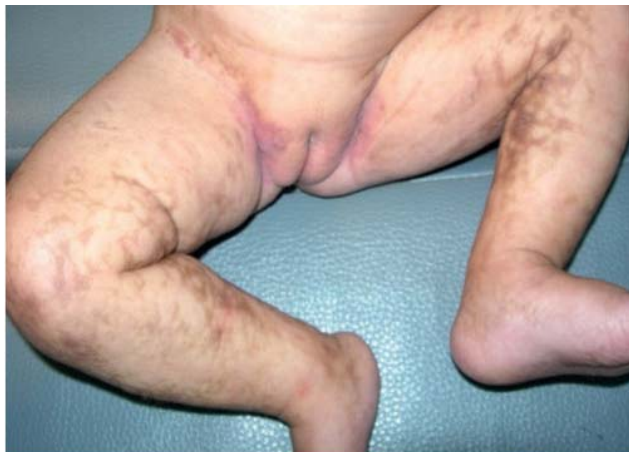

Figura 1. Ampollas e hiperpigmentación siguiendo las líneas de Blaschko.

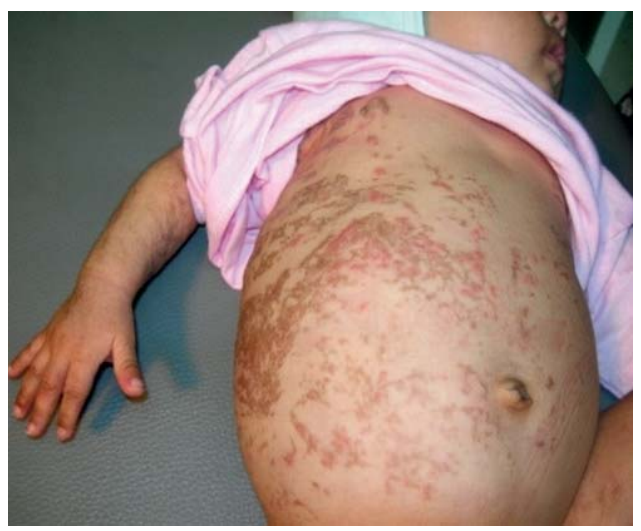

Figura 2. Hiperpigmentación y verrugas cerca a los pliegues de los muslos. Eritema perigenital.

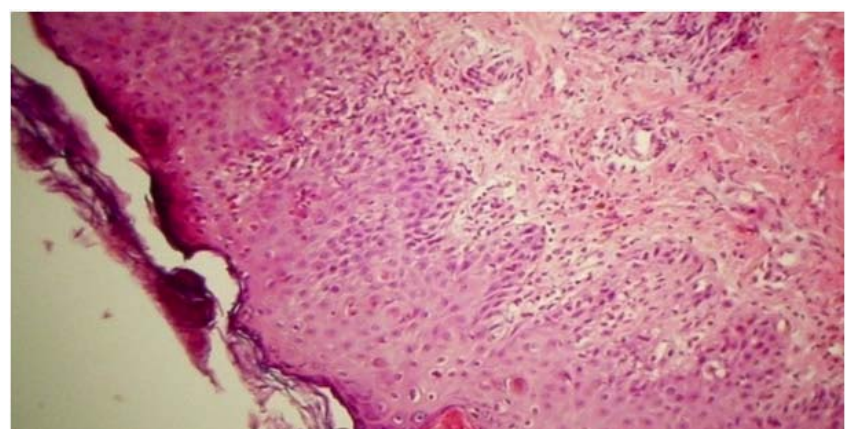

Figura 3. Estrato córneo sin cambios. Dermatitis espongiótica eosinofílica, vesículas intraepidérmicas rellenas de eosinófilos Células disqueratónicas en la capa espinosa. Algunas células con pigmento melánico en la capa basal 


\section{DISCUSIÓN}

La IP se debe a las mutaciones del gen NEMO (nuclear factor-kappa B essential modulator), localizadas en Xq28. NEMO es la subunidad reguladora del complejo lkb-cinasa necesaria para las vías de activación de NF-kB que desempeñan importantes papeles enla inflamación, respuesta inmunitaria, el control del crecimiento celular y la protección contra la apoptosis (4).

Como se mencionó previamente, a nivel histopatológico presenta cuatro estadios, cada uno con características particulares (5) (Tabla 1).

Para el diagnóstico se suele emplear los Criterios de Landy SJ y Donnai D (2). Existe ya una nueva versión (6).

Las manifestaciones clínicas graves incluyen: convulsiones, encefalopatía infantil, encefalomielitis diseminada aguda y el accidente cerebrovascular isquémico (7) y problemas oftalmológicos (8).

También, afectación en el pelo, las más frecuentes son: alopecia (placas) y pelo escaso (9). Por lo tanto se torna una enfermedad multisistémica y un reto para otras especialidades además de la dermatología.

En laboratorio (10), se ha reportado eosinofilia y leucocitosis entre la 3ra y 5 ta semana en la fase vesicular. Es importante, tener en cuenta a la displasia ectodérmica y la sífilis congénita como diagnósticos diferenciales. Las tres comparten manifestaciones comunes como la hipodoncia, microdoncia, malformaciones, dientes impactados y retraso de la erupción. Sin embargo, los dientes conoides de la IP son un rasgo característico que la diferencia de la sífilis congénita; además de que la displasia ectodérmica es recesiva y afecta más a varones.

La IP no tiene tratamiento específico hasta la actualidad; pero es importante recalcar la actitud profiláctica contra infecciones agregadas en los estadios vesiculares o verrugosos.

Es valioso conocer la IP debido a que se puede confundir con otras enfermedades de mayor prevalencia como el herpes, el nevus epidérmico lineal, entre otras, con el fin de evitar tratamiento inadecuado y sin éxito en la resolución de la enfermedad.

Muchos hospitales del país no cuentan con pruebas moleculares que son las definitivas e ideales para descartar otras enfermedades, de la Incontinentia pigmenti.

El caso expuesto cumple con los criterios mayores de Landy SJ y Donnai D, tratándose de un cuadro no severo (llamado también esporádico) estadio III (hiperpigmentado) con repercusiones estéticas que en la vida adulta, la paciente al salir embarazada, puede sufrir abortos espontáneos sin causa aparente o trasmitir la mutación a la descendencia. Por lo tanto, casos como éste, ameritan consejería genética.

Tabla 1. Hiperpigmentación y verrugas cerca a los pliegues de los muslos. Eritema perigenital.

\begin{tabular}{|c|c|}
\hline Estadio & Caracteristicas \\
\hline I.Vesiculoso & $\begin{array}{l}\text { Presencia de espongiosis con eosinófilos, vesículas epidérmicas } \\
\text { con eosinófilos en su interior y queratinocitos disqueratósicos. }\end{array}$ \\
\hline II.Verrugoso & $\begin{array}{l}\text { Presencia de acantosis, papilomatosis irregular e hiperqueratosis } \\
\text { dentro de las cuales hay presencia de células disqueratósicas } \\
\text { dispersas y degeneración con vacuolización de capa basal. }\end{array}$ \\
\hline III.Hiperpigmentado & $\begin{array}{l}\text { Presencia de melanófagos en el infiltrado inflamatorio. Melanina } \\
\text { libre en la dermis, pero con ausencia o disminución de la melanina } \\
\text { en la capa basal de la epidermis. }\end{array}$ \\
\hline IV.Atróficohipopigmentado & $\begin{array}{l}\text { Presencia de queratinocitos apoptósico, atrofia de los folículos } \\
\text { pilosos y ausencia del músculo piloerector. }\end{array}$ \\
\hline
\end{tabular}




\section{REFERENCIAS BIBLIOGRÁFICAS}

1. Orphanet Report Series. Prevalence of rare diseases: Bibliographic data. 2012, Disponible en:

http://www.orpha.net/orphacom/cahiers/docs/GB/Prevalence_ of_rare_diseases_by_alphabetical_list.pdf. Accedido Jul 4, 2013

2. Landy SJ, Donnai D: Incontinentia pigmenti (Bloch-Sulzberger syndrome).J Med Genet 1993, 30:53-59.

3. Sheuerle A. Male cases of incontinentia pigmenti: A case and review. Am J Med Genet. 1998; 77:201-18.

4. Smahi A, Courtois $G$, Vabres $P$ et al. Genomic rearrangement in NEMO impairs NF-jB activation and is a cause of incontinentia pigmenti. Nature 2000; 405: 466-472.

5. Hadj-Rabia S, Rimella A, Smahi A, et al. Clinical and histologic features of incontinentia pigmenti in adults with nuclear factor $\mathrm{KB}$ essential modulator gene mutations. J Am Acad Dermatol 2011; 64 (3): 508-15. Epub 2011 Jan 20.

6. Minic S, Trpinac D, Obradovic M. Incontinentia pigmenti diagnostic criteria. Update. Clin Genet 2014; 85: 536-542

7. Meuwissen M, Mancini G. Neurological findings in incontinentia pigmenti; a review. European Journal of Medical Genetics. 2012; vol 55(5):323-331

8. Francois J. Incontinentia pigmenti (Bloch-Sulzberger syndrome) and retinal changes. $\mathrm{Br} J$ Ophthalmol 1984; 68:19-25.

9. García García Alina, Hernández García Iván, de León Ojeda Norma, Acosta Sabatés Marta, Marrón Portales Lurdes. Revisión clínica de 28 casos de incontinencia pigmentaria. Rev Cubana Pediatr [revista en la Internet]. 2010 Sep [citado 2014 Jul 04] ; 82(3): 20-27. Disponible en: http://scielo.sld.cu/scielo.php?script=sci_ arttext\&pid=S0034-75312010000300003\&lng=es.

10. Berlin AL, Paller AS, Chan LS. Incontinentiapigmenti: A review and update on the molecular basis of pathophysiology. J Am Acad Dermatol. 2002; 47:169-89

\section{AGRADECIMIENTOS}

Nuestro especial agradecimiento al médico Dermatólogo Edgar Álvarez Llanos, quién nos facilitó el acceso a la historia clínica.

\section{Fuentes de financiamiento}

Autofinanciado por los autores.

\section{Conflictos de interés}

Los autores declaran no tener conflicto de interés en la presentación de este artículo.

\section{Correspondencia:}

Brayan Gálvez Marticorena

Dirección: Jr. Trinidad 269 Villa Jardín - San Luis

Teléfono: 4369316

Correo electrónico: brayan_galvez@usmp.pe 